\title{
Acoustic Presence of Dolphins through Whistles Detection in Mediterranean Shallow Waters
}

\author{
Martina Gregorietti ${ }^{1}$, Elena Papale ${ }^{1,2, *}$, Maria Ceraulo ${ }^{1} \mathbb{D}$, Clarissa de Vita ${ }^{1}$, Daniela Silvia Pace ${ }^{3} \mathbb{D}$, \\ Giorgio Tranchida ${ }^{1}$, Salvatore Mazzola ${ }^{1}$ and Giuseppa Buscaino ${ }^{1}{ }^{1 D}$
}

1 Unit of Capo Granitola, Institute of Anthropic Impacts and Sustainability in the Marine Environment (IAS), National Research Council, Via del Mare 3, 91021 Torretta Granitola, Italy; martina.gregorietti@gmail.com (M.G.); maria.ceraulo@ias.cnr.it (M.C.); claridevita@gmail.com (C.d.V.); giorgio.tranchida@cnr.it (G.T.); salvatore.mazzola@cnr.it (S.M.); giuseppa.buscaino@cnr.it (G.B.)

2 Department of Life Sciences and Systems Biology, University of Torino, Via Accademia Albertina 13, 10123 Torino, Italy

3 Department of Environmental Biology, Sapienza University of Rome, Viale dell’Università 32, 00185 Rome, Italy; danielasilvia.pace@uniroma1.it

* Correspondence: elena.papale@unito.it or elena.papale@cnr.it

Citation: Gregorietti, M.; Papale, E.; Ceraulo, M.; de Vita, C.; Pace, D.S.;

Tranchida, G.; Mazzola, S.; Buscaino, G. Acoustic Presence of Dolphins through Whistles Detection in Mediterranean Shallow Waters. J. Mar. Sci. Eng. 2021, 9, 78. https:// doi.org/10.3390/jmse9010078

Received: 2 December 2020

Accepted: 11 January 2021

Published: 13 January 2021

Publisher's Note: MDPI stays neutral with regard to jurisdictional clai$\mathrm{ms}$ in published maps and institutional affiliations.

Copyright: (C) 2021 by the authors. Licensee MDPI, Basel, Switzerland. This article is an open access article distributed under the terms and conditions of the Creative Commons Attribution (CC BY) license (https:// creativecommons.org/licenses/by/ $4.0 /)$.

\begin{abstract}
The evaluation of acoustic temporal rhythms in wide-ranging cetaceans can reveal patterns in animal spatial presence and the occurrence of periodical phenomena. Here, we aimed at assessing the temporal patterns of dolphin's acoustic presence in a shallow-water area in the Sicily Strait (Mediterranean Sea). Whistles were collected continuously for 14 months from an acoustic monitoring station installed aboard of an elastic seamark. Over a total of $6955 \mathrm{~h}$ of recording, 14,048 signals were identified using both automatic and visual methods. Three parameters were analyzed: hourly presence (HP), used as a proxy of the presence of dolphins in the area; detection rate (DR), indicating the acoustic activity rate of dolphins measured per hour in the entire dataset; and detection rate in presence of dolphins (DRD), indicating the acoustic activity rate of dolphins considering only the hours when whistles were recorded. The highest values of both HP and DR were reached during the night, and the Autumn and Winter months, suggesting an increase in the dolphin's occurrence and a possible moving away and towards the monitoring station potentially following prey. DRD, instead, showed an almost uniform distribution throughout the day implying that when the animals are close to the monitoring station, the acoustic activity does not show any pattern. However, possible changes in the communication exchange along the seasons were suggested. This study complements other work on this subject, improving the knowledge of dolphins' acoustic activity in the area.
\end{abstract}

Keywords: whistles; temporal patterns; bottlenose dolphin; solar elevation

\section{Introduction}

Environmental cycles such as seasonal changes, light and dark alternation, lunar phases and tidal cyclicity influence biological rhythms and may have either independent or cumulative effects on activity timing of living organisms [1]. Temporal organization based on environmental periodicity is commonly considered as an adaptive response to predictable variability of ecological factors and resources. Thus, living organisms often evolve their physiological, biological, and behavioral activity to match with key cycles affecting their habitat [2].

Many invertebrates and vertebrates show temporal patterns in their acoustic behavior, which are generally crucial for their life history [3-6]. Acoustics is critical for the survival of several living organisms, which rely on sounds for carrying on biological activities and communicating. Temporal and spatial patterns in the acoustic behavior of living organisms can therefore reveal several phenomena. Reproductive and mating behaviors are one of the ultimate causes of periodicity in acoustic activity, and substantial variations can occur along seasons and daytime [5,7-11]. 
Vocalizations and their patterns can be considered not only to study the spatiotemporal presence of species but also as a proxy for behavioral activities and for the habitat use. Dolphins are very social species and communication is pivotal to convey specific messages and information about activity, identity, sex, and age [12]. The signals mostly used for carrying out information about individual recognition [13,14], population identity [15-20], and belonging to a particular species [21-25] are tonal sounds. They are commonly used by both adults and juveniles, and the study of their temporal patterns can provide information about presence and timing of peculiar social behaviors within and between the groups [26].

Today, the majority of long-term acoustic studies focused on dolphin clicks, whose presence effectively revealed their daily and seasonal occurrence in an area, due to their consistent use by echolocating individuals [27-31]. Tonal sounds, on the contrary, being prevalently emitted during social context, have an emission rate lower than clicks, used as biosonar, and so far, their temporal trends have been explored prevalently in deep waters $[30,32,33]$.

Passive Acoustic Monitoring has been considered as a useful and cost-effective method to acquire information about the acoustic occurrence of dolphin populations on the longterm temporal scales [34,35], and to integrate information during nighttime and in bad weather conditions [36]. Moreover, long time series of data are crucial for studying circadian and seasonal rhythms in dolphins' acoustic activity [26,29]. Nevertheless, automatic sound detection from vast acoustic datasets could be challenging: in the last years, several methods were proposed [37] and efforts were made also to better describe [38] and discriminate dolphin vocalizations from other biological and anthropogenic sounds [39].

In the area of the Sicily Strait, a bottlenose dolphin population has been studied since 2005, along the North-Western coast of the channel. Recently, an acoustic yearround study [31], based on clicks analysis, identified a regular substantial occurrence with seasonal and diel variation. Dolphins spend most of the time in the area for feeding, and they actively interact with trawlers. Furthermore, a core of females with calves uses the area probably for foraging in high productive waters during longer periods compared to other individuals [40]. However, little is known about their movement and the timing of social interactions.

This study aimed to fill these gaps by assessing the seasonal and circadian occurrence of whistles in this shallow water area within the Mediterranean Sea, using an autonomous and fixed monitoring station.

\section{Materials and Methods}

\subsection{Study Area}

The acoustic monitoring station was installed aboard of an elastic seamark in the North-Western coast of the Sicily Strait $\left(37^{\circ} 31.05^{\prime} \mathrm{N}, 12^{\circ} 39.19^{\prime} \mathrm{E}\right.$; see Figure 1$), 5 \mathrm{~km}$ far from the coastal seaside of Capo Granitola (South-Western of Sicily).

The Sicily Strait is characterized by diverse oceanographic features, which generate the establishment of a permanent upwelling that enriches with organic substances in the superficial water levels, supplying the food cycles of both coastal and pelagic communities [41,42]. This phenomenon makes the area a biodiversity hotspot of the Mediterranean Sea, also for cetacean species [43-47].

Considering the distance from the coast, the depth at which the device was positioned (45 m), and in agreement with other studies conducted in the same location [40,48], the dolphin species predominantly recorded in the area is the bottlenose dolphin. The studied bottlenose dolphin population is known to have a low site fidelity, moving also outside the study site. Moreover, females with calves used the area longer than other individuals [40]. 


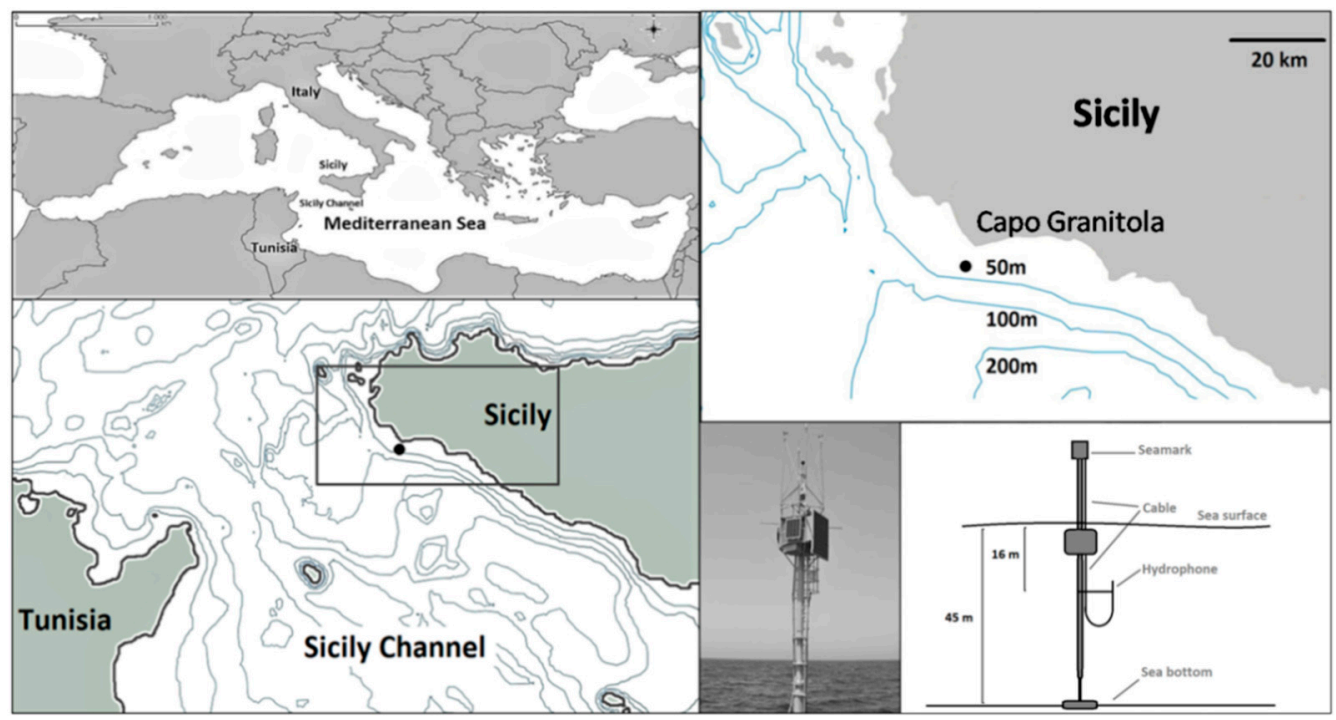

Figure 1. Location of the acoustic device in the Sicily Strait (Mediterranean Sea) and graphical representation of the hydrophone deployment.

\subsection{Acoustic Data Collection}

A monitoring station was installed on the seamark since 2012. It consisted of a hydrophone (ResonTC4014, Denmark) with a sensitivity of $-180 \pm 3 \mathrm{~dB}$ re: $1 \mathrm{~V} / \mu \mathrm{Pa}$ in the frequency range from $25 \mathrm{~Hz}$ to $250 \mathrm{kHz}$, deployed $16 \mathrm{~m}$ below the surface and connected to a digital acquisition card (USGH 416HB, Avisoft Bioacoustics, Berlin, Germany, set at $20 \mathrm{~dB}$ gain). An embedded fanless computer (AMOS-3005-1Q12A1, Via Technologies, USA) operated the acquisition through a dedicated Avisoft Recorder USGH software (Avisoft Bioacoustics), located on the top of the seamark. In order to reduce the noise from the mooring components, the seamark was anchored with an antitorsion iron cable.

The device provided continuous fine-scale temporal recordings along the year, and data used for this study were collected from 5 January 2015 to 28 February 2016. However, due to forced stops for technical maintenance of the beacon and the hydrophone during the 14 months, data were not collected from 17 March to 21 April and from 16 September to 9 October 2015. Furthermore, during September, a lower number of minutes per hour was recorded. Acoustic data were collected at a sampling frequency of $50 \mathrm{kHz}$ (16 bits) and stored in $5 \mathrm{~min}$ recordings files (with no time gap among consecutive files) to facilitate processing and analysis. Overall, 84,056 files were considered for the analyses, with a total of 326 days and 417,272 min of recording. A number of 14,048 dolphin whistles was detected for the whole period (see Table 1).

\subsection{Acoustic Data Processing}

The Silbido contour detector [49] software was used to automatically extract dolphin tonal calls.

In order to estimate accuracy, the number of True Negative (TN), True Positive (TP), False Negative (FN), and False Positive (FP) were evaluated on a subsample of 27,220 files $(32 \%)$ visually inspected (Table 2, first panel). Basing on the estimation of the number of whistles per file, False Positive Ratio (FPR), True Negative Ratio (TNR), and Sensitivity (Table 2, second panel) were calculated. The software showed a moderate sensitivity (0.75) and a low accuracy (0.52) (Table 2, second panel, first row), with a tendency to overestimate the number of whistles per file $(\mathrm{FPR}=0.5)$, mainly when boat passages were acoustically recorded (Figure 2). 
Table 1. Sampling effort and number of the vocalizations distributed along the study period.

\begin{tabular}{|c|c|c|c|c|c|c|}
\hline & & Days Recorded & Min Recorded & $\mathbf{N}^{\circ}$ of Files & $\begin{array}{c}\mathbf{N}^{\circ} \text { of Whistles } \\
\text { Detected }\end{array}$ & $\begin{array}{c}\mathrm{N}^{\circ} \text { of } \\
\text { Whistles/Min rec }\end{array}$ \\
\hline & January & 22 & 26,405 & 5281 & 914 & 0.035 \\
\hline & February & 24 & 24,690 & 4938 & 818 & 0.033 \\
\hline & March & 16 & 23,025 & 4605 & 931 & 0.04 \\
\hline & April & 9 & 12,045 & 2409 & 339 & 0.028 \\
\hline & May & 31 & 44,635 & 8927 & 1160 & 0.026 \\
\hline \multirow[t]{7}{*}{2015} & June & 30 & 43,200 & 8640 & 997 & 0.023 \\
\hline & July & 27 & 37,180 & 7436 & 383 & 0.01 \\
\hline & Agoust & 29 & 39,925 & 7985 & 1248 & 0.031 \\
\hline & September & 15 & 1397 & 881 & 10 & 0.007 \\
\hline & October & 22 & 31,000 & 6200 & 1318 & 0.043 \\
\hline & November & 16 & 19,910 & 3982 & 1022 & 0.051 \\
\hline & December & 31 & 43,480 & 8696 & 2567 & 0.059 \\
\hline \multirow[t]{3}{*}{2016} & January & 28 & 34,990 & 6998 & 1393 & 0.04 \\
\hline & February & 26 & 35,390 & 7078 & 948 & 0.027 \\
\hline & Tot & 326 & 417,272 & 84,056 & 14,048 & \\
\hline
\end{tabular}

Table 2. Confusion matrix (first panel) and associated metrics (second panel) calculated for the number of whistles and considering the first and the definitive assessments.

\begin{tabular}{|c|c|c|c|c|c|c|}
\hline Metrics & Accuracy & $\begin{array}{l}\text { False Positive Rate } \\
\text { (FPR or Fall-out) }\end{array}$ & $\begin{array}{c}\text { True Negative } \\
\text { Rate (TNR or } \\
\text { Specificity) }\end{array}$ & $\begin{array}{c}\text { True Positive } \\
\text { Rate (TPR, } \\
\text { Recall or } \\
\text { Sensitivity) }\end{array}$ & Precision & F-Score \\
\hline \multirow{4}{*}{$\begin{array}{c}\text { First } \\
\text { assessment } \\
\text { Definitive } \\
\text { assessment }\end{array}$} & $\begin{array}{c}(\mathrm{TN}+\mathrm{TP}) / \\
(\mathrm{TN}+\mathrm{TP}+\mathrm{FN}+\mathrm{FP})\end{array}$ & $\mathrm{FP} /(\mathrm{TN}+\mathrm{FP})$ & $\mathrm{TN} /(\mathrm{TN}+\mathrm{TP})$ & $\mathrm{TP} /(\mathrm{TP}+\mathrm{FN})$ & $\mathrm{TP} / \mathrm{TP}+\mathrm{FP}$ & $\begin{array}{c}(2 * \text { TPR } * \text { Prec }) \\
(\text { TPR+Prec })\end{array}$ \\
\hline & 0.52 & 0.5 & 0.49 & 0.75 & 0.15 & 0.24 \\
\hline & 0.97 & 0 & 0.98 & 0.69 & 1 & 0.82 \\
\hline & First assessment & $\begin{array}{c}\text { Definitive } \\
\text { assessment }\end{array}$ & & & & \\
\hline $\begin{array}{l}\text { True Positive } \\
\text { (TP) }\end{array}$ & 3607 & 1933 & & & & \\
\hline $\begin{array}{l}\text { True Negative } \\
\text { (TN) }\end{array}$ & 20,498 & 79,600 & & & & \\
\hline $\begin{array}{l}\text { False Positive } \\
\text { (FP) }\end{array}$ & 21,240 & 0 & & & & \\
\hline $\begin{array}{l}\text { False Negative } \\
\text { (FN) }\end{array}$ & 1164 & 875 & & & & \\
\hline
\end{tabular}

In order to improve accuracy and eliminate the overestimation, all the files containing more than 3 signals $(n=2416)$ were visually checked and the number of whistles was corrected accordingly. For the visual check, Avisoft-SASLab Pro (with 1024 Fast Fourier Transform size and Hamming window, with 50\% overlap; Avisoft Bioacoustics, Berlin, Germany) was used. A whistle was defined as a tonal signal for which at least a part of the contour was clearly definable even if overlapped with other signals. Figure 2 shows the spectrograms of a whistle correctly detected by the software (A), and of overlapped whistles that needed the visual check for updating to the correct number $(B)$. Then, out of the files containing $1-3$ signals $(n=13,590)$, the $20 \%(n=2718)$ was randomly selected and visually checked to estimate a possible error generated by the software. In this case, 2429 (90\% of the checked files) did not contain whistles. Thus, all the files identified by the software with a number of whistles from 1 to 3 were considered without whistles. 
Overall, 32,354 files (38\% of the total 84,056 files) were visually inspected using AvisoftSASLab Pro.

The visual checks improved the number of detected whistles, leading to zero the number of FP. The accuracy increased from 0.52 to 0.97 and the sensitivity decreased from 0.75 to 0.69 , making the final count more conservative (Table 2 , second panel, second row).

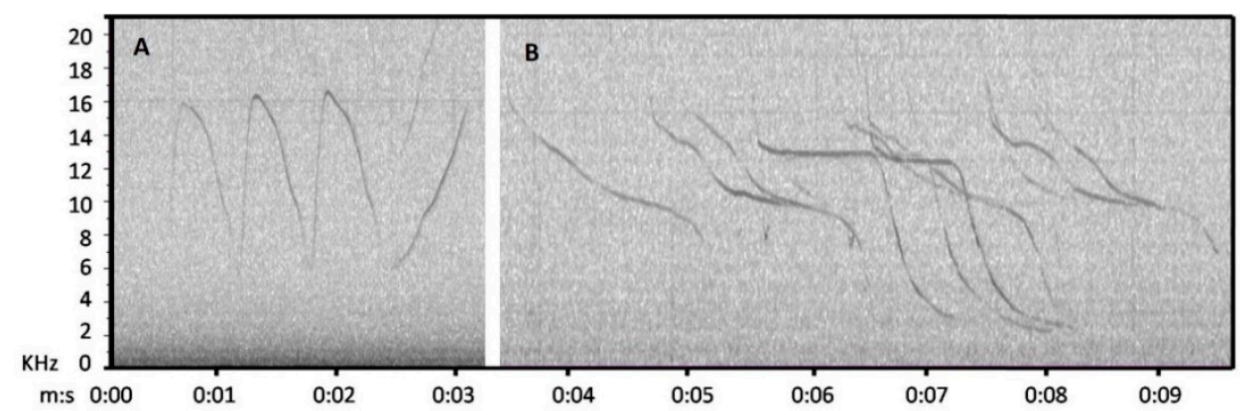

Figure 2. Spectrograms (1024 points FFT with Hamming window and 50\% overlap) of two detections are here represented: $\mathbf{A}$. shows a whistle correctly detected by the automatic software and $\mathbf{B}$. represents a detection with 11 overlapped whistles that needed the visual assessment for updating to the correct number.

\subsection{Diel and Seasonal Analysis}

In order to investigate trends in whistles occurrence, and study the temporal pattern of vocalizations considering any possible effect of dolphins' movement on vocal abundance, three variables were calculated as follows:

Hourly presence (HP), binary variable, defined as the presence (1) or absence (0) of dolphin whistles in a $-\mathrm{h}$ time interval.

Detection rate (DR), i.e., as the number of whistles divided by the minutes recorded in an hour.

Detection rate in presence of dolphins whistles (DRD), i.e., as the number of whistles divided by the minutes recorded in an hour with dolphin presence (i.e., when $\mathrm{HP}>0$ ).

Hourly presence (HP) was used as a proxy of the acoustic presence of dolphins in the area. DR, indicating the acoustic activity rate of dolphins, was measured in the entire dataset, and DRD, defining the acoustic activity rate of the animals, was calculated only when the signals were recorded. This last parameter was chosen to identify any possible timing of peculiar social context during which dolphins aggregate or increase the need of communicate [50].

The analysis about the effect of light intensity on the acoustic activity pattern of dolphins was performed by considering the position of the sun as solar elevation angles with respect to the horizon line. Positive and negative values of solar elevation angles indicated, respectively, presence or absence of the sun irradiation, while the absolute value is a proxy of the distance from the horizon. The solar elevation angles were obtained as output of MATLAB function "SolarAzEl" (programmed by D. C. Koblick, 2013) after inputting the geographical coordinates, the elevation (in $\mathrm{m}$ ) above sea level, and the UTC time. Considering light conditions, the day was subdivided into three periods: Day (solar elevation values $>+10^{\circ}$ ), Night (solar elevation values $<-10^{\circ}$ ), and Twilight (solar elevation values between $-10^{\circ}$ and $+10^{\circ}$ ).

Further, in order to evaluate seasonal patterns, data were subdivided in seasons as Winter (from 21 December to 20 March), Spring (from 21 March to 20 June), Summer (from 21 June to 22 September), and Autumn (from 23 September to 20 December).

\subsection{Statistical Analysis}

All data were tested for normality through a Kolmogorov-Smirnov test [51] and, since were not normally distributed, nonparametric tests were applied. The Kruskal-Wallis (KW) [52] and the multiple comparisons post hoc (MC) [53] tests were used to check any 
differences in the median values of whistles occurrence (DR, HP, and DRD) between the periods of the day and the seasons. These tests apply assumptions for spatial and temporal independence and no pseudoreplication, but not for normality or equal variances. The software STATISTICA 8.0 (StatSoftInc., USA) was used for the analysis.

\section{Results}

\subsection{Overall}

Table 1 summarized the number of files analyzed per month and the number of whistles detected. Totally, 14,048 tonal vocalizations were counted in $6955 \mathrm{~h}$. Whistles were present all along the months from January 2015 to February 2016.

\subsection{Seasonal Pattern}

Considering the monthly pattern, in general, the highest values of HP and DR were recorded in November and December, whereas the lowest values were recorded in July and September. Maximum DRD values were found in October and December, while the minimum values were found in September, April, and July (Figure 3).
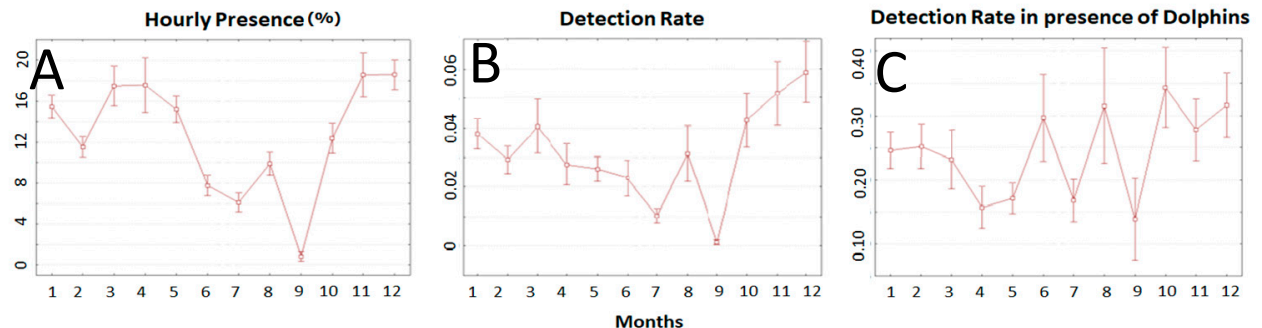

Figure 3. Mean monthly distribution of the acoustic parameters considered (A hourly presence (HP), B detection rate (DR), C detection rate in presence of dolphins (DRD)).

By analyzing the seasons (Figure 4 and Table 3), HP showed the lowest values during summer and the highest values in the Autumn and Winter; the detection rate was lower in Spring and Summer considering the entire dataset (DR) and only in Spring considering the dataset containing whistles (DRD).
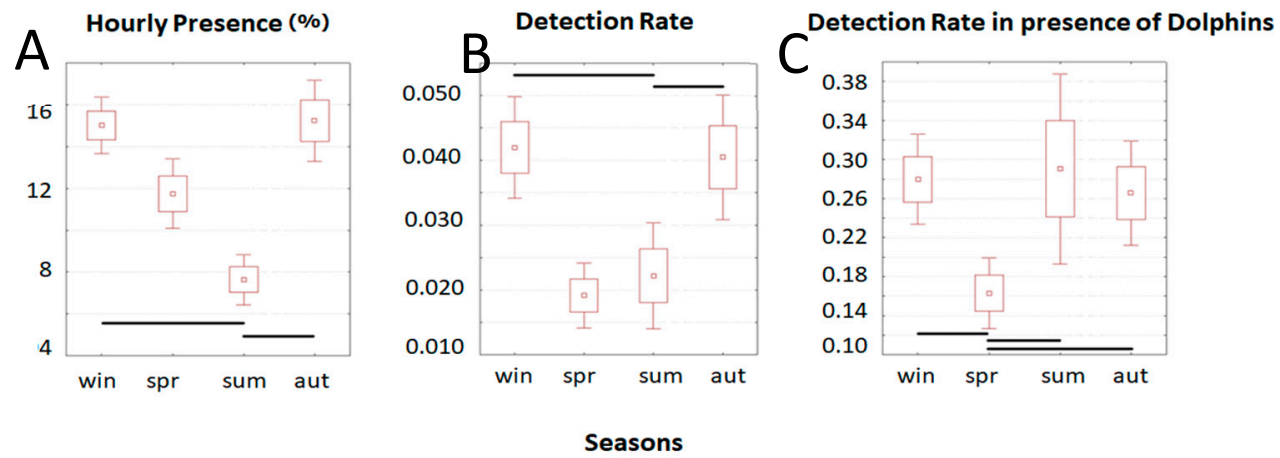

Figure 4. Mean seasonal distribution of acoustic parameters considered (A HP, B DR, and C DRD). Black lines indicate significant differences between seasons (multiple comparison test, $p<0.05$, see red significant values in Table 3), whiskers represent the 0.95 confidence intervals and boxes represent the standard errors. 
Table 3. Results of Kruskal-Wallis test (left column) and multiple comparison $Z^{\prime}$ values (right column) for hourly presence $(\mathrm{HP})$, detection rate (DR), and detection rate in presence of dolphins (DRD) considering the differences between seasons. Significant values are represented in red $(p<0.05$, critical value $=2.57)$ of the multiple comparison tests. HP and DR showed significant differences in Summer compared to Winter and Autumn months, while DRD values were significantly lower in Spring compared to all the other seasons.

\begin{tabular}{|c|c|c|c|c|c|}
\hline & & Winter & Spring & Summer & Autumn \\
\hline & Winter & & 1.728 & 4.249 & 0.116 \\
\hline Hourly presence & Spring & 1.728 & & 2.027 & 1.584 \\
\hline \multirow[t]{2}{*}{ Kruskal-Wallis Chi test: $65.9, p<0.001$} & Summer & 4.249 & 2.027 & & 3.664 \\
\hline & Autumn & 0.116 & 1.584 & 3.664 & \\
\hline \multirow{4}{*}{$\begin{array}{c}\text { Detection rate } \\
\text { Kruskal-Wallis Chi test:66.5, } p<0.001\end{array}$} & Winter & & 1.861 & 4.250 & 0.151 \\
\hline & Spring & 1.861 & & 1.904 & 1.727 \\
\hline & Summer & 4.250 & 1.904 & & 3.697 \\
\hline & Autumn & 0.151 & 1.727 & 3.697 & \\
\hline \multirow{4}{*}{$\begin{array}{l}\quad \begin{array}{c}\text { Detection rate in presence of } \\
\text { whistles }\end{array} \\
\text { Kruskal-Wallis Chi test: } 13.5, p<0.004\end{array}$} & Winter & & 3.110 & 0.311 & 0.693 \\
\hline & Spring & 3.110 & & 2.780 & 3.303 \\
\hline & Summer & 0.311 & 2.780 & & 0.271 \\
\hline & Autumn & 0.693 & 3.303 & 0.271 & \\
\hline
\end{tabular}

\subsection{Diel Patterns}

Circadian trends of the HP, DR, and DRD in different seasons are showed in Figure 5, together with the sun elevation. Although HP and DR showed similar temporal patterns (Figure 6), differences between the three periods of the day (night, twilight, and light) emerged (Figure 6). In general, the highest values of both variables were reached during the night (Figure 5 and Figure 6), with weaker but still significant differences in Winter (KW test results in $p<0.05$, Figure 6). They increased along the seasons, with a peak in Autumn both for HP and DR. In this season, HP and DR values at night were statistically different both from the day and from twilight, while during Spring and Summer, there were significant differences only between day and night. However, if we consider the DRD, those differences completely disappeared (KW test results in $p>0.05$; Figure 6 ). Indeed, there were no substantial variations between the different day periods during the seasons with the exception of Summer, where DRD is higher during nighttime (Figure 6).

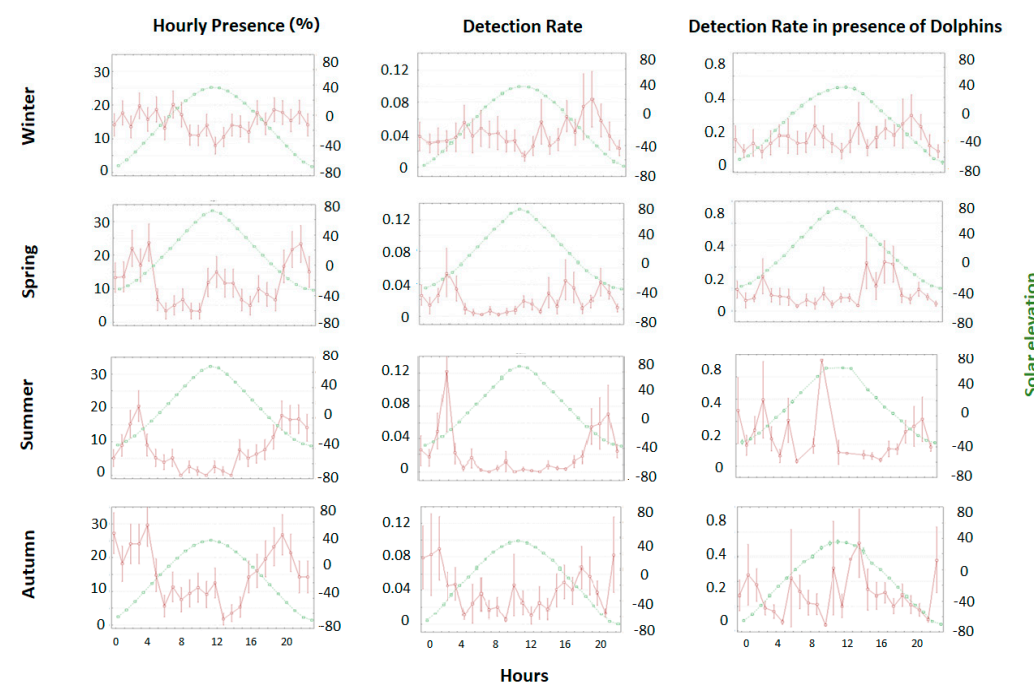

Figure 5. From the left to the right: mean HP, DR, and DRD during the four seasons and in relation to solar elevation. Red lines and symbols are for HP, DR, and DRD and green lines and symbols are for the solar elevation. Error bars represent the standard errors and hour is referred to UTC (Coordinated Universal Time) time. When bars are not evident, the error is very low. 

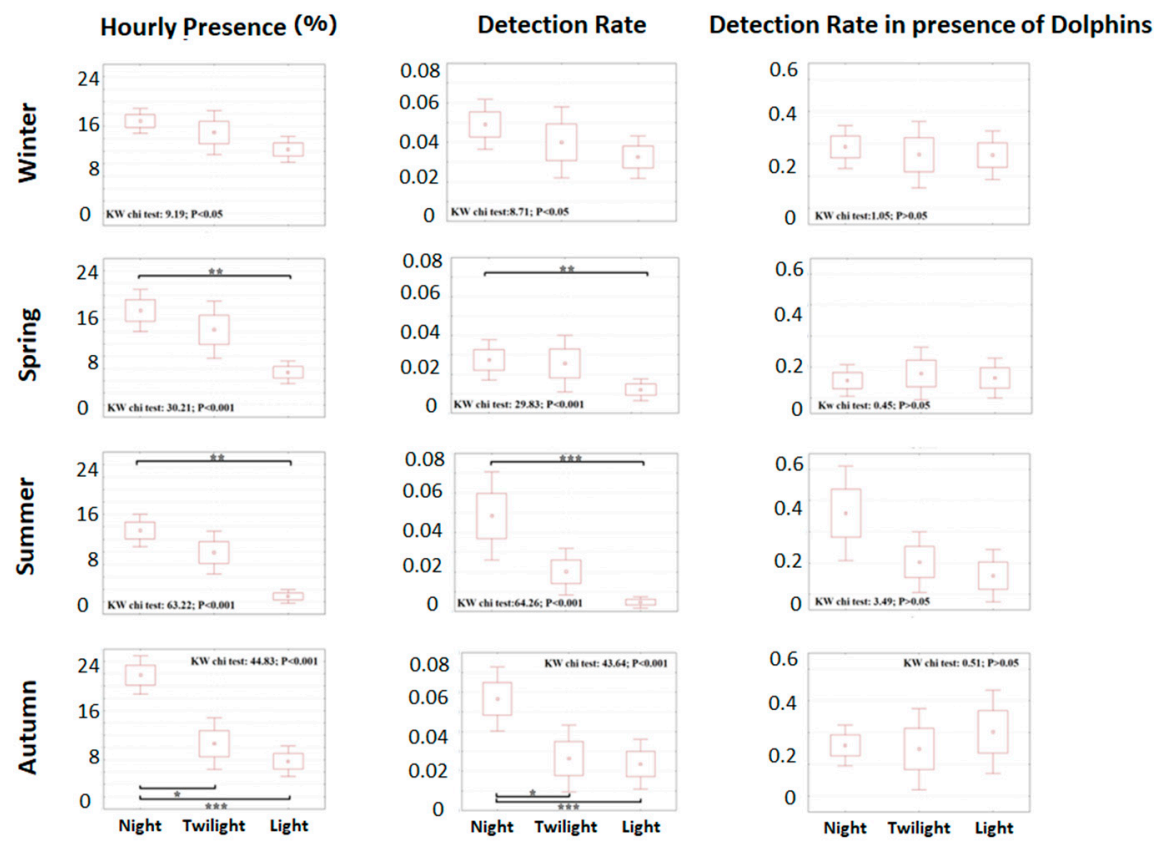

Periods of the day

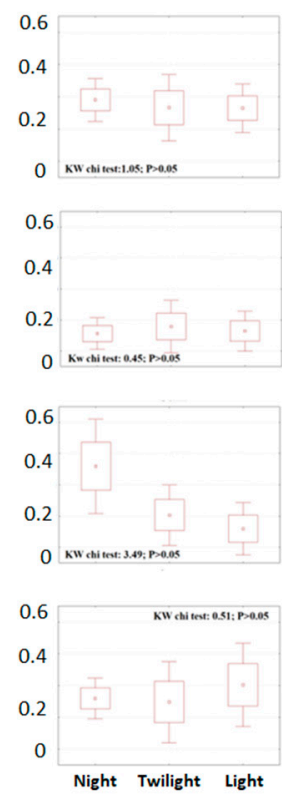

Figure 6. From the left to the right: mean HP, DR, and DRD for the three periods of the day, considering the four seasons. Whiskers represent the 0.95 confidence intervals; boxes represent the standard errors. Black bold horizontal brackets represent significant differences between the periods of the day; ${ }^{*}{ }^{* *}$, and ${ }^{* * *}$ asterisks, respectively, indicate a $p$-value of $0.05,0.01$, and 0.001 .

\section{Discussion}

This work has demonstrated that tonal sounds collected through an acoustic fixed station are effective and powerful to provide long-term information on the acoustic presence, temporal trends, and possible behavioral changes of dolphins in shallow waters. Whistles were detected all year-round, suggesting that delphinid usage of the study region was regular and confirming that the area is a key habitat for their survival [31,40].

Whistle Hourly Presence and Detection Rate were significantly higher during dark hours compared to day or twilight. A trend was evident with the lowest value during the day, an average value during twilight, and the highest along the night, with the strongest differences in Autumn.

The presence of differences in DR and HP along the day and the absence of variations in DRD (except for a trend during Summer) suggest that dolphins spend more time whistling in the area during the night, and that during Autumn they move towards the coast after sunset. DRD results suggest no differences in the number of whistles emitted per hour when the dolphins stay in the area. However, a trend was showed during the Summer, implying not only a major dolphin presence during the night compared to the rest of the day, as from HP and DR outcomes, but also a possible increase in the social communication exchange, possibly due to the occurrence of mother-calf social interactions.

These may have important implications in understanding dolphin habitat-use, however, hours or seasons with lower detection rates may simply indicate reduced movement into the study area, fewer individuals, or transitory occupancy potentially determined by changes in foraging opportunities [54]. Diel patterns are reported in several studies, which revealed that dolphin acoustic activity generally decreases during daytime $[26,32,55]$ and is greater during nighttime, when possibly foraging [29,56-58]. However, whistle detection rate outcomes from around the world are heterogeneous, showing in some areas an absence of temporal trends, while elsewhere a general decrease during daytime [26,32,57].

By analyzing whistles pattern along the months, dolphins seemed to be acoustically more present during Autumn and Winter than Spring and Summer, a result similar to the one reported by Papale and colleagues, which used clicks as cues for animal presence [31]. 
Indeed, higher click rates were obtained during November, suggesting an increase in the occurrence of individuals in the area possibly attracted by prey availability. In September, the lowest detection rate in both clicks and whistles may be related to the annual shutdown of fisheries for biological recovery occurring along Sicilian coasts (as for Administrative order 15A05454-July 3, 2015, GU 162, a decrease in the trawling effort was applied following the management plans for the fish stocks in the Sicily Strait). Since dolphins frequently interact with fishing boats as source of food [59-61], it seems likely that this behavior may have influenced their occurrence and that animals followed trawlers offshore. Furthermore, during this month, a lower number of minutes per hour were recorded. Even if the HP could have been affected by this bias, the DR and the DRD cannot have been influenced due to their formulation, thus providing a feasible clue about the context.

Surprisingly, the detection rate in presence of dolphins (DRD) showed different trends compared to the DR and HP, especially in June and August. Maximum DRD values were found in October, December, August, and June, while the minimum values were found in September, April, July, and May. This suggests that dolphins increase the communication exchange during the first ones. During the Summer, the peak of birth period is recorded for Mediterranean bottlenose dolphins [62,63]. In the study area, mother-calf pairs are regularly sighted and show a high degree of site fidelity [40]. Coupling this information with the increased vocalization rate in Summer, we may assume that such higher values are related to the intensification of whistle exchanges during mother-calf social interactions.

On the other end, during Autumn, also the HP and DR were higher, suggesting an increase in the dolphin's occurrence in these coastal waters.

These outcomes strongly encourage the integrated use of all acoustic data (whistles and clicks) originated from passive acoustic monitoring stations, even with the geographical and temporal limitations that affect such investigations. Acoustic data can efficiently complement visual surveys, and a detailed analysis of the whistle parameters could provide relevant information on the habits of the dolphin community to be integrated in marine spatial planning programs, especially in coastal areas where the interactions with human activities increase the conservation risks for dolphin species [36].

Author Contributions: Conceptualization, E.P. and G.B.; methodology, E.P. and G.B.; software validation and formal analysis M.G., M.C., and C.d.V.; resources and funding, G.T., S.M., D.S.P., and G.B.; writing, all authors. All authors have read and agreed to the published version of the manuscript.

Funding: This research received no external funding.

Institutional Review Board Statement: Not applicable.

Informed Consent Statement: Not applicable.

Data Availability Statement: The data presented in this study are available on request from the corresponding author.

Acknowledgments: Authors would like to thank Buffa G., Calandrino P., Giacalone V.M., and Grammauta R. for their support during installation and maintenance operations of the monitoring station.

Conflicts of Interest: The authors declare no conflict of interest.

\section{References}

1. Yamahira, K. How do multiple environmental cycles in combination determine reproductive timing in marine organisms? A model and test. Funct. Ecol. 2004, 18, 4-15. [CrossRef]

2. Dunlap, J.C.; Loros, J.; DeCoursey, P. Chronobiology: Biological Timekeeping; Sinauer: Sunderland, MA, USA, 2004.

3. MacIntyre, K.Q.; Stafford, K.M.; Berchok, C.L.; Boveng, P.L. Year-round acoustic detection of bearded seals (Erignathus barbatus) in the Beaufort Sea relative to changing environmental conditions, 2008-2010. Polar Biol. 2013, 36, 1161-1173. [CrossRef]

4. Locascio, J.V.; Mann, D.A. Diel and seasonal timing of sound production by black drum (Pogonias cromis). Fish. Bull. 2011, 109, 327-338.

5. $\quad$ Buscaino, G.; Ceraulo, M.; Pieretti, N.; Corrias, V.; Farina, A.; Filiciotto, F.; Maccarrone, V.; Grammauta, R.; Caruso, F.; Alonge, G.; et al. Temporal patterns in the soundscape of the shallow waters of a Mediterranean marine protected area. Sci. Rep. 2016, 6, 34230. [CrossRef] [PubMed] 
6. De Vincenzi, G.; Parisi, I.; Torri, M.; Papale, E.; Mazzola, S.; Nuth, C.; Buscaino, G. Influence of environmental parameters on the use and spatiotemporal distribution of the vocalizations of bearded seals (Erignathus barbatus) in Kongsfjorden, Spitsbergen. Polar Biol. 2019, 42, 1241-1254. [CrossRef]

7. Simon, M.; Stafford, K.M.; Beedholm, K.; Lee, C.M.; Madsen, P.T. Singing behavior of fin whales in the Davis Strait with implications for mating, migration and foraging. J. Acoust. Soc. Am. 2010, 128, 3200-3210. [CrossRef]

8. Vieira, M.; Pereira, B.P.; Pousão-Ferreira, P.; Fonseca, P.J.; Amorim, M. Seasonal variation of captive meager acoustic signalling: A manual and automatic recognition approach. Fishes 2019, 4, 28. [CrossRef]

9. Ceraulo, M.; Sal Moyano, M.P.; Bazterrica, M.C.; Hidalgo, F.J.; Papale, E.; Grammauta, R.; Gavio, M.A.; Mazzola, S.; Buscaino, G. Spatial and temporal variability of the soundscape in a Southwestern Atlantic coastal lagoon. Hydrobiologia 2020, 847, 2255-2277. [CrossRef]

10. McCauley, R. Fish choruses from the Kimberley, seasonal and lunar links as determined by long term sea noise monitoring. In Acoustics, Development and the Environment, Proceedings of the 2012 Acoustics Conference, Fremantle, Australia, 21-23 November 2012; McMinn, T., Ed.; Acoustical Society of Australia: Fremantle, Australia, 2012.

11. Ceraulo, M.; Papale, E.; Caruso, F.; Filiciotto, F.; Grammauta, R.; Parisi, I.; Mazzola, S.; Farina, A.; Buscaino, G. Acoustic comparison of a patchy Mediterranean shallow water seascape: Posidonia oceanica meadow and sandy bottom habitats. Ecol. Ind. 2018, 85, 1030-1043. [CrossRef]

12. Janik, V.M.; Sayigh, L.S. Communication in bottlenose dolphins: 50 years of signature whistle research. J. Comp. Physiol. A 2013, 199, 479-489. [CrossRef]

13. Caldwell, M.C.; Caldwell, D.K. Individualized whistle contours in bottle-nosed dolphins (Tursiops truncatus). Nature 1965, 207, 434-435. [CrossRef]

14. Fripp, D.; Owen, C.; Quintana-Rizzo, E.; Shapiro, A.; Buckstaff, K.; Jankowski, K.; Wells, R.; Tyack, P. Bottlenose dolphin (Tursiops truncatus) calves appear to model their signature whistles on the signature whistles of community members. Anim. Cogn. 2005, 8, 17-26. [CrossRef] [PubMed]

15. Jones, G.J.; Sayigh, L.S. Geographic variation in rates of vocal production of free-ranging bottlenose dolphins. Mar. Mammal Sci. 2002, 18, 374-393. [CrossRef]

16. Papale, E.; Azzolin, M.; Cascao, I.; Gannier, A.; Lammers, M.O.; Martin, V.M.; Oswald, J.; Perez-Gil, M.; Prieto, R.; Silva, M.A.; et al. Geographic variability in the acoustic parameters of striped dolphin's (Stenella coeruleoalba) whistles. J. Acoust. Soc. Am. 2013, 133, 1126-1134. [CrossRef]

17. Papale, E.; Azzolin, M.; Cascão, I.; Gannier, A.; Lammers, M.O.; Martin, V.M.; Oswald, J.; Perez-Gil, M.; Prieto, R.; Silva, M.A.; et al. Acoustic divergence between bottlenose dolphin whistles from the Central-Eastern North Atlantic and Mediterranean Sea. Acta Ethologica 2014, 17, 155-165. [CrossRef]

18. Papale, E.; Azzolin, M.; Cascão, I.; Gannier, A.; Lammers, M.O.; Martin, V.M.; Oswald, J.; Perez-Gil, M.; Prieto, R.; Silva, M.A.; et al. Macro and micro geographic variation of short-beaked common dolphin's whistles in the Mediterranean Sea and Atlantic Ocean. Ethol. Ecol. Evol. 2014, 26, 392-404. [CrossRef]

19. Gridley, T.; Nastasi, A.; Kriesell, H.; Elwen, S. The acoustic repertoire of wild common bottlenose dolphins (Tursiops truncatus) in Walvis Bay, Namibia. Bioacoustics 2015, 24, 153-174. [CrossRef]

20. Azzolin, M.; Gannier, A.; Papale, E.; Buscaino, G.; Mussi, B.; Ardizzone, G.; Giacoma, C.; Pace, D.S. Whistle variability of the Mediterranean short beak common dolphin. Aquat. Conserv. Mar. Freshw. Ecosyst. 2019, 1-15. [CrossRef]

21. Oswald, J.N.; Barlow, J.; Norris, T.F. Acoustic identification of nine delphinid species in the eastern tropical Pacific Ocean. Mar. Mammal Sci. 2003, 19, 20-037. [CrossRef]

22. Oswald, J.N.; Rankin, S.; Barlow, J.; Lammers, M.O. A tool for real-time acoustic species identification of delphinid whistles. J. Acoust. Soc. Am. 2007, 122, 587-595. [CrossRef]

23. Gannier, A.; Fuchs, S.; Quèbre, P.; Oswald, J.N. Performance of a contour-based classification method for whistles of Mediterranean delphinids. Appl. Acoust. 2010, 71, 1063-1069. [CrossRef]

24. Azzolin, M.; Gannier, A.; Lammers, M.O.; Oswald, J.N.; Papale, E.; Buscaino, G.; Buffa, G.; Mazzola, S.; Giacoma, C. Combining whistle acoustic parameters to discriminate Mediterranean odontocetes during passive acoustic monitoring. J. Acoust. Soc. Am. 2014, 135, 502-512. [CrossRef]

25. Erbs, F.; Elwen, S.H.; Gridley, T. Automatic classification of whistles from coastal dolphins of the southern African subregion. J. Acoust. Soc. Am. 2017, 141, 2489-2500. [CrossRef]

26. Lin, T.-H.; Yu, H.-Y.; Chen, C.-F.; Chou, L.-S. Passive acoustic monitoring of the temporal variability of odontocete tonal sounds from a long-term marine observatory. PLoS ONE 2015, 10, e0123943. [CrossRef]

27. Soldevilla, M.S.; Wiggins, S.M.; Hildebrand, J.A. Spatial and temporal patterns of Risso's dolphin echolocation in the Southern California Bight. J. Acoust. Soc. Am. 2010, 127, 124-132. [CrossRef]

28. Baumann-Pickering, S.; Roch, M.A.; Brownell, R.L., Jr.; Simonis, A.E.; McDonald, M.A.; Solsona-Berga, A.; Oleson, E.M.; Wiggins, S.M.; Hildebrand, J.A. Spatio-temporal patterns of beaked whale echolocation signals in the North Pacific. PLoS ONE 2014, 9, e86072.

29. Castellote, M.; Brotons, J.M.; Chicote, C.; Gazo, M.; Cerdà, M. Long-termacoustic monitoring of bottlenose dolphins, Tursiops truncatus, in marine protected areas in the Spanish Mediterranean Sea. Ocean Coast. Manag. 2015, 113, 54-66. [CrossRef] 
30. Caruso, F.; Alonge, G.; Bellia, G.; De Domenico, E.; Grammauta, R.; Larosa, G.; Mazzola, S.; Riccobene, G.; Pavan, G.; Papale, E.; et al. Long-Term monitoring of dolphin biosonar activity in deep pelagic waters of the Mediterranean Sea. Sci. Rep. 2017, 7, 4321. [CrossRef]

31. Papale, E.; Alonge, G.; Grammauta, R.; Ceraulo, M.; Giacoma, C.; Mazzola, S.; Buscaino, G. Year-round acoustic patterns of dolphins and interaction with anthropogenic activities in the Sicily Strait, central Mediterranean Sea. Ocean Coast. Manag. 2020, 197, 105320. [CrossRef]

32. Goold, J.C. A diel pattern in vocal activity of short-beaked common dolphins, Delphinus delphis. Mar. Mammal Sci. 2000, 16, 240-244. [CrossRef]

33. Hodge, L.E.W.; Bell, J.T.; Kumar, A.; Read, A.J. The influence of habitat and time of day on the occurrence of odontocete vocalizations in Onslow Bay, North Carolina. Mar. Mammal Sci. 2013, 29, E411-E427. [CrossRef]

34. Palmer, K.J.; Brookes, K.L.; Davies, I.M.; Edwards, E.; Rendell, L. Habitat use of a coastal delphinid population investigated using passive acoustic monitoring. Aquat. Conserv. Mar. Freshw. Ecosyst. 2019, 29, 254-270. [CrossRef]

35. Todd, N.R.E.; Cronin, M.; Luck, C.; Bennison, A.; Jessopp, M.; Kavanagh, A.S. Using passive acoustic monitoring to investigate the occurrence of cetaceans in a protected marine area in northwest Ireland. Estuar. Coast. Shelf Sci. 2020, 232, 106509. [CrossRef]

36. Thompson, P.M.; Brookes, K.L.; Cordes, L.S. Integrating passive acoustic and visual data to model spatial patterns of occurrence in coastal dolphins. ICES J. Mar. Sci. 2015, 72, 651-660. [CrossRef]

37. Papale, E.; Alonge, G.; Caruso, F.; Grammauta, R.; Mazzola, S.; Mussi, B.; Pace, D.S.; Buscaino, G. The higher, the closer, the better? Influence of sampling frequency and distance on the acoustic properties of short-beaked common dolphins burst pulses in the Mediterranean Sea. Aquat. Conserv. Mar. Freshw. Ecosyst. 2019, 1-10. [CrossRef]

38. Halkias, X.C. Detection and Tracking of Dolphin Vocalizations. Ph.D. Thesis, Columbia University, New York, NY, USA, 2009.

39. Siddagangaiah, S.; Chen, C.-F.; Hu, W.-C.; Akamatsu, T.; McElligott, M.; Lammers, M.O.; Pieretti, N. Automatic detection of dolphin whistles and clicks based on entropy approach. Ecol. Indic. 2020, 117, 106559. [CrossRef]

40. Papale, E.; Ceraulo, M.; Giardino, G.; Buffa, G.; Filiciotto, F.; Grammauta, R.; Maccarrone, V.; Mazzola, S.; Buscaino, G. Association patterns and population dynamics of bottlenose dolphins in the Strait of Sicily (Central Mediterranean Sea): Implication for management. Popul. Ecol. 2016, 59, 55-64. [CrossRef]

41. Bonanno, A.; Placenti, F.; Basilone, G.; Mifsud, R.; Genovese, S.; Patti, B.; Di Bitetto, M.; Aronica, S.; Barra, M.; Giacalone, G.; et al Variability of water mass properties in the Strait of Sicily in summer period of 1998-2013. Ocean Sci. 2014, 10, 759. [CrossRef]

42. Di Lorenzo, M.; Sinerchia, M.; Colloca, F. The North sector of the Strait of Sicily: A priority area for conservation in the Mediterranean Sea. Hydrobiologia 2018, 821, 235-253. [CrossRef]

43. Benmessaoud, R.; Chérif, M.; Bradai, M.N.; Bejaoui, N. Distribution of bottlenose dolphin around Kelibia (Northeastern of Tunisia). Asian J. Contemp. Sci. 2012, 1, 1-11.

44. Bearzi, G.; Reeves, R.R.; di Sciara, G.N.; Politi, E.; Canadas, A.N.A.; Frantzis, A.; Mussi, B. Ecology, status and conservation of short-beaked common dolphins Delphinus delphis in the Mediterranean Sea. Mammal Rev. 2003, 33, 224-252. [CrossRef]

45. Bearzi, G.; Reeves, R.R.; Remonato, E.; Pierantonio, N.; Airoldi, S. Risso's dolphin Grampus griseus in the Mediterranean Sea. Mammal Biol. 2011, 76, 385-400. [CrossRef]

46. Canese, S.; Cardinali, A.; Fortuna, C.M.; Giusti, M.; Lauriano, G.; Salvati, E.; Greco, S. The first identified winter feeding ground of fin whales (Balaenoptera physalus) in the Mediterranean Sea. J. Mar. Biol. Assoc. 2006, 86, 903. [CrossRef]

47. Aïssi, M.; Celona, A.; Comparetto, G.; Mangano, R.; Würtz, M.; Moulins, A. Large-scale seasonal distribution of fin whales (Balaenoptera physalus) in the central Mediterranean Sea. J. Mar. Biol. Assoc. 2008, 88, 1253. [CrossRef]

48. Buscaino, G.; Buffa, G.; Filiciotto, F.; Maccarrone, V.; Di Stefano, V.; Ceraulo, M.; Mazzola, S.; Alonge, G. Pulsed signal properties of free-ranging bottlenose dolphins (Tursiops truncatus) in the central Mediterranean Sea. Mar. Mammal Sci. 2015, 31, 891-901. [CrossRef]

49. Roch, M.A.; Brandes, T.S.; Patel, B.; Barkley, Y.; Baumann-Pickering, S.; Soldevilla, M.S. Automated extraction of odontocete whistle contours. J. Acoust. Soc. Am. 2011, 130, 2212-2223. [CrossRef]

50. Quick, N.J.; Janik, V.M. Whistle rates of wild bottlenose dolphins (Tursiops truncatus): Influences of group size and behavior. J. Comp. Psychol. 2008, 122, 305. [CrossRef]

51. Massey, F.J., Jr. The Kolmogorov-Smirnov test for goodness of fit. J. Am. Stat. Assoc. 1951, 46, 68-78. [CrossRef]

52. McKight, P.E.; Najab, J. Kruskal-wallis test. In The Corsini Encyclopedia of Psychology; John Wiley \& Sons: New York, NY, USA, 2010.

53. Jaccard, J.; Becker, M.A.; Wood, G. Pairwise multiple comparison procedures: A review. Psychol. Bull. 1984, 96, 589. [CrossRef]

54. Silva, T.L.; Mooney, A.; Sayigh, L.S.; Baumgartner, M.F. Temporal and spatial distributions of delphinid species in Massachusetts Bay (USA) using passive acoustics from ocean gliders. Mar. Ecol. Prog. Ser. 2019, 631, 1-17. [CrossRef]

55. Deconto, L.S.; Monteiro-Filho, E.L. Day and night sounds of the Guiana dolphin, Sotalia guianensis (Cetacea: Delphinidae) in southeastern Brazil. Acta Ethologica 2016, 19, 61-68. [CrossRef]

56. Lammers, M.O.; Howe, M.; Zang, E.; McElligott, M.; Engelhaupt, A.; Munger, L. Acoustic monitoring of coastal dolphins and their response to naval mine neutralization exercises. R. Soc. Open Sci. 2017, 4, 170558. [CrossRef]

57. Nuuttila, H.K.; Courtene-Jones, W.; Baulch, S.; Simon, M.; Evans, P.G. Don't forget the porpoise: Acoustic monitoring reveals fine scale temporal variation between bottlenose dolphin and harbour porpoise in Cardigan Bay SAC. Mar. Biol. 2017, 164, 50. [CrossRef] [PubMed] 
58. Wingfield, J.E.; O’Brien, M.; Lyubchich, V.; Roberts, J.J.; Halpin, P.N.; Rice, A.N.; Bailey, H. Year-round spatiotemporal distribution of harbour porpoises within and around the Maryland wind energy area. PLoS ONE 2017, 12, e0176653. [CrossRef] [PubMed]

59. Pace, D.S.; Pulcini, M.; Triossi, F. Anthropogenic food patches and association patterns of Tursiops truncatus at Lampedusa island, Italy. Behav. Ecol. 2012, 23, 254-264. [CrossRef]

60. Buscaino, G.; Buffa, G.; Sara, G.; Bellante, A.; Tonello, A.J.; Hardt, F.A.S.; Cremer, M.J.; Bonanno, A.; Cuttitta, A.; Mazzola, S. Pinger affects fish catch efficiency and damage to bottom gill nets related to bottlenose dolphins. Fish. Sci. 2009, 75, 537-544. [CrossRef]

61. Pace, D.S.; Giacomini, G.; Campana, I.; Paraboschi, M.; Pellegrino, G.; Silvestri, M.; Alessi, J.; Angeletti, D.; Cafaro, V.; Pavan, G.; et al. An integrated approach for cetacean knowledge and conservation in the central Mediterranean Sea using research and social media data sources. Aquat. Conserv. Mar. Freshw. Ecosyst. 2019, 29, 1302-1323. [CrossRef]

62. Bearzi, G.; di Sciara, G.N.; Politi, E. Social ecology of bottlenose dolphins in the Kvarnerić (northern Adriatic Sea). Mar. Mammal Sci. 1997, 13, 650-668. [CrossRef]

63. Blasi, M.F.; Bruno, C.; Boitani, L. Female reproductive output in a Mediterranean bottlenose dolphin Tursiops truncatus population. Aquat. Biol. 2020, 29, 123-136. [CrossRef] 